\section{Concrete scalp in trauma}

Sir,

The scalp as a donor site for the skin graft was first described by Crawford in 1964. ${ }^{[1]}$ The scalp as a donor site allows multiple skin graft harvests. However, multiple complications, including bleeding, alopecia, exudative crusting/"concrete scalp deformity," staphylococcal folliculitis have been described..$^{[2,3]}$

Concrete scalp deformity is a condition seen when thickness of harvested skin graft is more than $0.2 \mathrm{~mm} \cdot .^{[1,4]}$ It is characterised by a boggy granulating mass with enmeshed growing hair. However, this condition is not reported after trauma.

Deep abrasions in the scalp occurring due to trauma if not treated properly or neglected can lead to infection and proliferation of granulation tissue leading to a condition similar to "concrete scalp deformity" seen after medium thickness skin graft harvested from the scalp.

We report a case of neglected abrasion over the scalp following trauma that presented to us after 3 weeks. This lead to the proliferation of the granulation tissue leading to a mulberry - like swelling over the abrasion site with embedded hair that bled on touch [Clinical: Figure 1a]. A working diagnosis of foreign body granuloma or concrete scalp deformity was made. A wedge biopsy of the swelling was sent for histopathology. The proliferative granulation tissue was scraped. The histopathology showed inflammatory granulation tissue [Histology: Figures 2a and b]. The culture from wound grew Staphylococcus aureus. The wound was covered with a split thickness skin graft [Clinical: Figure 1b].

Deep abrasion of the scalp may sound inconspicuous. If neglected, it can delay wound healing with concrete scalp deformity like picture. The wound should be cleaned well to avoid formation of scabs and dressed with occlusive dressings. Gauze should be avoided as a dressing. Although described only for scalp as a donor site, concrete scalp can happen after head trauma. The clinician must be aware of this condition and treat early to prevent alopecia.

\section{Soumya Gupta, Amish Gohil, Ashish Kumar Gupta}

Department of Plastic Surgery, Christian Medical Collage and Hospital, Vellore, Tamil Nadu, India

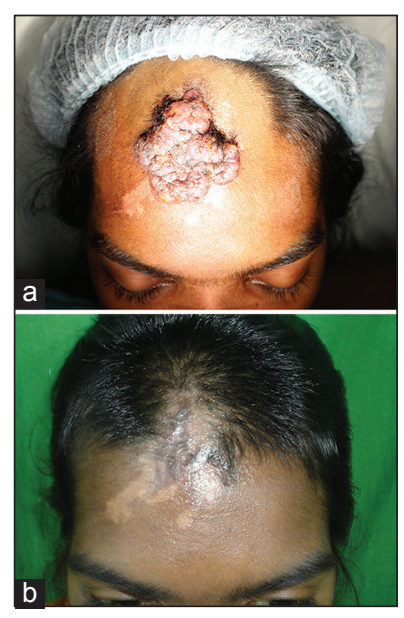

Figure 1: (a) Clinical preoperative image showing a $4 \mathrm{~cm} \times 3 \mathrm{~cm}$ mulberry like swelling over the forehead abrasion site. (b) Clinical postoperative image showing areas of spontaneous epithelisation and growth of hair

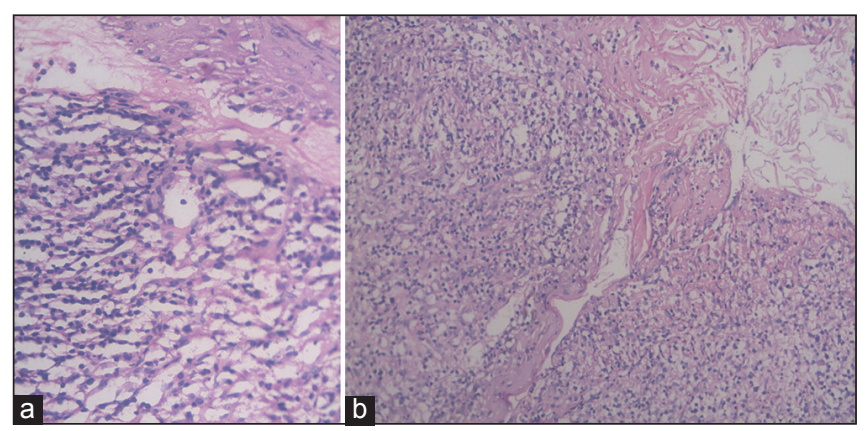

Figure 2: (a) Histopathological image showing dermal inflammation (×40 magnification). (b) Histopathological image showing ulceration with fibrin $(\times 20$ magnification $)$

Address for correspondence: Dr. Soumya Gupta, Department of Plastic Surgery, Christian Medical Collage and Hospital, Vellore - 632 004, Tamil Nadu, India. E-mail: minisom6@yahoo.co.in

\section{REFERENCES}

1. Crawford BS. AN unusual skin donor site. $\mathrm{Br} J$ Plast Surg 1964;17:311-3.

2. Engrav LH, Grube BJ, Bubak PJ. Treatment of the concrete scalp donor site. Ann Plast Surg 1990;24:162-4.

3. Lesesne CB, Rosenthal R. Areview of scalp split-thickness skin grafts and potential complications. Plast Reconstr Surg 1986;77:757-8.

4. Carter YM, Summer GJ, Engrav LH, Hansen FL, Costa BA, Matsumura $\mathrm{H}$. Incidence of the concrete scalp deformity associated with deep scalp donor sites and management with the Unna cap. J Burn Care Rehabil 1999;20:141-4.

\begin{tabular}{|l|l|}
\hline \multicolumn{2}{|c|}{ Access this article online } \\
\hline Quick Response Code: & Website: \\
\hline & www.ijps.org \\
\cline { 2 - 3 } & Dol: \\
\hline
\end{tabular}

